\title{
Diethylene Glycol in Health Products Sold Over-the-Counter and Imported from Asian Countries
}

\author{
Joshua G. Schier • Dana B. Barr • Zheng Li • \\ Amy F. Wolkin • Samuel E. Baker • Lauren S. Lewis • \\ Michael A. McGeehin
}

Published online: 7 October 2010

(C) American College of Medical Toxicology 2010

\begin{abstract}
Diethylene glycol (DEG), a chemical that has been implicated in multiple medication-associated mass poisonings, can result in renal and neurological toxicity if ingested. Three previous such mass poisonings implicated Chinese manufacturers as the origin of contaminated ingredients. No literature exists on potential DEG or triethylene glycol (TEG), a related compound, contamination of health products imported from Asian countries to the USA. Our primary objective was to quantitatively assess the amount of DEG present in a convenience sampling of these health products. The study's secondary objectives were to: (1) evaluate for, and quantify TEG levels in these samples; (2) compare DEG and TEG levels in these products directly to levels in medications implicated in previous similar mass poisonings; and (3) to estimate DEG dose (in $\mathrm{mg} / \mathrm{kg}$ ) based on the manufacturer's instructions and compare these values to toxic doses from past mass poisonings and the literature. A quantitative assessment of DEG and TEG was performed in a convenience sampling of over-the-counter health products imported from Asian countries. Results were converted to volume to volume $(v / v) \%$ and compared with DEG levels in medications implicated in previous mass poisonings. Estimated doses (based on the manufacturer's instructions) of each product with detectable levels of DEG for a $70 \mathrm{~kg}$ adult were compared to toxic doses of DEG reported in the literature. Seventeen of $85(20 \%)$ samples were not able to be analyzed for DEG or TEG due to technical reasons. Fifteen of $68(22 \%)$ samples successfully tested had detectable
\end{abstract}

J. G. Schier $(\bowtie) \cdot$ D. B. Barr · Z. Li • A. F. Wolkin · S. E. Baker •

L. S. Lewis · M. A. McGeehin

Centers for Disease Control and Prevention,

Atlanta, USA

e-mail: jschier@cdc.gov levels of DEG (mean, $18.8 \mu \mathrm{g} / \mathrm{ml}$; range, $0.791-110.1 \mu \mathrm{g} / \mathrm{ml}$; and volume to volume $(v / v)$ range, $0.00007-0.01 \%)$. Two of $68(3 \%)$ samples had TEG levels of 12.8 and $20.2 \mu \mathrm{g} / \mathrm{ml}$ or $0.0012 \%$ and $0.0018 \%$ TEG $v / v$. The product with the highest $\mathrm{DEG} \%$ by $v / v$ was 810 times less than the product involved in the Panama DEG mass poisoning (8.1\%). The lowest reported toxic dose from a past DEG mass poisoning $(14 \mathrm{mg} / \mathrm{kg}$ ) was more than 150 times higher than the highest daily dose estimated in our study $(0.09 \mathrm{mg} / \mathrm{kg})$. Sixty-eight of $85(80 \%)$ samples were able to be successfully analyzed for DEG and TEG. DEG and TEG were detectable in 15/68 $(22 \%)$ and 2/68 (3\%) samples, respectively. Based on current standards, these levels probably do not represent an acute public health threat. Additional research focusing on why DEG is found in these products and on the minimum amount of DEG needed to result in toxicity is needed.

Keywords Diethylene glycol · Health · Over-the-counter . Supplement

\section{Background}

Diethylene glycol (DEG) is used in antifreeze, brake fluids, cosmetics, lubricants, and other commercially available products. It causes renal insufficiency and failure, peripheral neuropathy, encephalopathy, coma, and death [1]. At least ten DEG mass poisonings have occurred over the past 70 years. These mass poisonings were all caused by DEG-contaminated liquid or ointment medications. DEG contamination occurs when it is used in medicinal products instead of a safer-but more expensive-diluent such as pharmaceutical grade glycerin [2]. In at least three of these reports, the implicated raw materials were either reported to have been manufactured by Chinese manufac- 
turers and exported or used in-country [2-6]. Recently, a wide variety of toothpastes that were made in China and contaminated with DEG were found in several countries including the USA [7]. A recent investigation into a DEG mass poisoning involving an over-the-counter health product in Nigeria identified another inappropriate and related ingredient, triethylene glycol (TEG), in product samples. The concentrations of TEG and DEG in these products were highly correlated (Pearson's correlation $0.989, p<0.0001$ ), suggesting an association with each other (Dana Barr, Ph.D., Centers for Disease Control and Prevention, personal communication, 2009). TEG is an ethylene glycol derivative that has been used in certain brake fluid formulations. It has been reported to cause coma and metabolic acidosis when ingested in extremely large amounts [8-10]. It is important to note that although TEG may have some inherent toxicity at large doses and was found as a co-contaminant in medication samples from the Nigeria DEG mass poisoning, the majority of toxicity is most likely due to DEG. These events prompted the study authors to hypothesize that other health products, such as dietary supplements, imported from China and other Asian countries may have DEG and/or TEG as a possible contaminant or ingredient.

The primary objective of this study was to determine and quantify the level of DEG, if present, in a convenience sampling of over-the-counter health products imported from Asian countries and sold locally (Chamblee, Georgia). The study's secondary objectives were to: (1) evaluate for, and quantify TEG levels in these samples; (2) compare DEG and TEG levels in these products directly to levels in medications implicated in previous similar mass poisonings; and (3) to estimate DEG dose (in $\mathrm{mg} / \mathrm{kg}$ ) based on the manufacturer's instructions and compare these values to toxic doses from past mass poisonings and the literature.

\section{Methodology}

Study investigators obtained a convenience sample of overthe-counter health products from nine different stores that sell Asian medicinal products in the Chamblee, Georgia, area during March 2009. Stores were located through a local directory, the Chinese Medicine and Medical Section of the Chinese Yellow Pages. To be included in this study health products had to be: (1) imported from an Asian country; (2) a liquid or ointment based product; and (3) sold over the counter (non-prescription).

Pills were not included because DEG is a liquid and contamination of a solid product was considered unlikely. Product origin was confirmed by visual inspection of the packaging and translation by a scientist fluent in Chinese when indicated. Store owners were informed as to the general study purpose if they asked. The principal investigator then classified samples into one of seven general categories for descriptive analysis: dietary/herbal supplements, eye drops/ointment, ear drops/ointment, miscellaneous healthrelated tonics, nasal spray, throat/cough syrups, or topical agent. The National Center for Environmental Health's Division of Laboratory Sciences then analyzed these samples for the presence of DEG and TEG.

\section{Laboratory Analysis}

A high-performance liquid chromatography/tandem mass spectrometry method was used to analyze the samples and measure concentrations of both DEG and TEG. Isotopically labeled DEG (d8) was used as an internal standard for quantifying both DEG and TEG. The sample was diluted, 1:100 or 1:1,000 depending on expected concentrations, with purified water before injection. The eluting compounds were converted to gas phase molecular ions by positive atmospheric pressure chemical ionization. The molecular ions were first mass filtered with unit resolution, then fragmented by collision activated dissociation, resulting in product ions that were subsequently filtered with unit resolution before being detected. Resulting chromatographic peaks were quantified using a 12-point standard curve. The limit of detection (LOD) can be lowered by diluting the pharmaceutical product with less water without sacrificing other method parameters. The LOD is a statistically calculated value that consists of the average detectable level for an analyte over an entire set of runs. A peak can sometimes be identified that is below the LOD but is not quantifiable. In these cases, additional volume of product was used and backcalculations performed. The accuracy ranged from $97.8 \%$ to $104.2 \%$. The relative standard deviations ranged from $12 \%$ to $16 \%$. The LODs for DEG and TEG based on a 1:1000 dilution of the product were 6.3 and $1.8 \mathrm{mcg} / \mathrm{ml}$, respectively.

\section{Comparisons and Estimated Dose Calculations}

To compare results from this study to DEG and TEG levels from implicated medicines in previous outbreaks, sample results were converted to volume-to-volume $(v / v)$ concentrations. Percents of DEG and TEG were determined on a $v / v$ basis by converting the microgram units to gram units then dividing by the density of DEG or TEG (both have densities of approximately $1.1 \mathrm{~g} / \mathrm{ml}$ ) to determine the amount in milliliters of DEG or TEG. The resulting number was then multiplied by 100 to get a percentage. These values were then compared to the results of percentages of DEG or TEG $v / v$ in contaminated medications from mean or median values of the three most recent DEG mass poisonings where data were available (Haiti 1995, Panama 
2006, and Nigeria 2009). We calculated the DEG amount consumed from one single dose and the daily maximum dose for a 70-kg adult for each product based on the manufacturer's instructions. These results were then compared to toxic or lethal doses of DEG reported in the scientific literature from past DEG mass poisonings and to the reported dose associated with acute toxicity in humans from the literature.

\section{Results}

\section{Description of Samples}

A convenience sample of 85 products was collected from nine stores that sold products meeting the inclusion criteria in the Chamblee, GA area during March of 2009. These products included: oral dietary/herbal supplements $(n=48)$, throat/cough syrups $(n=11)$, eye drops/ointment $(n=10)$, topical agents (including eye ointments; $n=10$ ), miscellaneous health-related tonics $(n=4)$, nasal spray $(n=1)$, and ear drops/ ointment $(n=1)$. The products we purchased originated from China $(n=71)$, Hong Kong $(n=10)$, Singapore $(n=2)$, Taiwan $(n=1)$, or Malaysia $(n=1)$.

\section{Diethylene Glycol and TEG Level Testing Results and Description}

Of the 85 samples tested for DEG, 17 (20\%) were not analyzable because they were not water-soluble (a prerequisite for the analytical method used). Of the 68 analyzable samples, 53 (78\%) had values below the LOD of the method with no discernable evidence that any DEG was present and $15(22 \%)$ samples had detectable levels of DEG. Five of the $15(33 \%)$ samples with detectable levels of DEG initially were reported as "detectable but not quantifiable levels"; however, the sample was reanalyzed using ten times the volume and a quantified result was reported based on back-calculations (concentration divided by a factor of ten). Of the 15 samples with detectable and quantifiable levels of DEG, the mean was $18.8 \mu \mathrm{g} / \mathrm{ml}$, the median was $7.12 \mu \mathrm{g} / \mathrm{ml}$, and the range was $0.791-110.1 \mu \mathrm{g} / \mathrm{ml}$ (Table 1). Among products with detectable levels of DEG, the $v / v$ range was $0.00007-0.01 \%$. The 15 products with detectable levels of DEG were purchased from six different stores.

Of the 85 samples tested for TEG, 17 (20\%) were not analyzable because they were not water-soluble (a prerequisite for the analytical method used). Of the 68 analyzable samples, 66 (97\%) samples had values below the LOD of the method with no discernable evidence that any TEG was present by LC/MS, and two (3\%) samples were positive. The two TEG-positive samples were also positive for DEG. The two samples with detectable levels were 12.8 and $20.2 \mu \mathrm{g} / \mathrm{ml}$ (Table 1). The two products with detectable levels of TEG had values of $0.0012 \%$ and $0.0018 \%$ TEG $v / v$. The two products with detectable levels of TEG were purchased from a single store.

Of the 15 specimens that tested positive for DEG, five either had specific dosing instructions for children or mentioned that the product could be used for children. (Table 2) Eight products did not specifically mention children and two were topically applied agents.

Comparison of Testing Results to DEG and TEG Levels Found in Medications from Previous Mass Poisonings

The median percent DEG $v / v$ for medications implicated in the 1995 Haiti mass poisoning was $14.4 \%$ [3]. The mean percent DEG $v / v$ in medications from the 2006 Panama mass poisoning was $8.1 \%$ [4]. The mean percent DEG $v / v$ for medications from the recent mass poisoning in 2009 Nigeria was $19.3 \%$. (Dana Barr, Ph.D., CDC, personal communication, 2009). All products from this investigation have a percent DEG by $v / v$ far less than the mean and median values from past mass poisonings. In fact, the product with the highest percent DEG by $v / v$ (sample 17 , $0.01 \%$ ) was 810 times less than what was seen in Panama, which had the lowest percent DEG $v / v$ of the three aforementioned DEG mass poisonings.

Regrettably, information about TEG in the literature is scarce, but TEG is considered to have a low order of toxicity [9]. Only two reports of human poisoning could be found in the medical literature $[8,10]$. Neither of these reports mentioned or calculated a toxic or lethal dose. In the Nigeria DEG mass poisoning, the TEG $v / v$ was $0.6 \%$ (Dana Barr, Ph.D., CDC, personal communication, 2009). By comparison, the TEG $v / v$ values in this study were $0.0012 \%$ and $0.0018 \%$, or $333-500$ times lower than the values found in the Nigeria DEG mass poisoning.

\section{Estimated DEG Doses Compared with Toxic Doses Reported in the Literature}

Based on sample 17 in our study, the highest estimated single dose in a $70-\mathrm{kg}$ adult was $0.031 \mathrm{mg} / \mathrm{kg}$ (range, $0.0001-0.031 \mathrm{mg} / \mathrm{kg}$ ), and the highest estimated daily maximum dose in a 70-kg adult was $0.09 \mathrm{mg} / \mathrm{kg}$ (range, $0.0002-0.09 \mathrm{mg} / \mathrm{kg}$ ) (Table 3). Historical data on median or average doses associated with toxicity or lethality from past medication-associated, DEG mass poisonings are limited. Following are the available data: USA (1937), $1.0 \mathrm{ml} \mathrm{DEG/}$ $\mathrm{kg}$ or approximately $1,118 \mathrm{mg} / \mathrm{kg}[1,11]$; Argentina (1992), 14-174 mg DEG/kg [1, 12-14]; Haiti (1995), $1.34 \mathrm{ml}$ DEG/kg or approximately $1,500 \mathrm{mg} / \mathrm{kg}$ [3]; Panama (2006), $310 \mathrm{mg} / \mathrm{kg}$ (Nestor Sosa, MD, unpublished data, 2009). In comparison, the more conservative toxic minimum value $(14 \mathrm{mg} / \mathrm{kg}$ ) of these four mass poisoning events (Argentina, 
Table 1 Quantitative DEG/TEG testing results and product information for samples with positive results for DEG $(n=15)$

\begin{tabular}{|c|c|c|c|c|c|c|c|}
\hline Sample ID & $\begin{array}{l}\text { DEG level } \\
(\mathrm{mcg} / \mathrm{ml})\end{array}$ & $\begin{array}{l}\text { TEG level } \\
(\mathrm{mcg} / \mathrm{ml})\end{array}$ & $\begin{array}{l}\text { \% DEG volume } \\
\text { by volume }\end{array}$ & $\begin{array}{l}\% \text { TEG volume } \\
\text { by volume }{ }^{b}\end{array}$ & Product name & General classification & Origin \\
\hline 0003 & $5.7^{\mathrm{a}}$ & $<$ LOD & 0.0005 & $<$ LOD & Cough Be Gone & Throat/Cough syrup & China \\
\hline 0016 & 73.4 & $<\mathrm{LOD}$ & 0.007 & $<\mathrm{LOD}$ & White Flower Analgesic balm & Topical agent & Hong Kong \\
\hline 0017 & 110.0 & $<\mathrm{LOD}$ & 0.01 & $<\mathrm{LOD}$ & $\begin{array}{l}\text { PH Balance Plus } \\
\text { (Tong Fong Ning) }\end{array}$ & Dietary/Herbal supplement & China \\
\hline 0022 & $0.791^{\mathrm{a}}$ & $<\mathrm{LOD}$ & 0.00007 & $<\mathrm{LOD}$ & $\begin{array}{l}\text { Sanshedan Chuanbei } \\
\text { Ye-HEI Brand }\end{array}$ & Dietary/Herbal supplement & China \\
\hline 0027 & $2.22^{\mathrm{a}}$ & $<$ LOD & 0.0002 & $<$ LOD & Hanban Liquid & Topical agent & China \\
\hline 0029 & 15.2 & $<$ LOD & 0.0014 & $<$ LOD & $\begin{array}{l}\text { First Lady Cough and } \\
\text { Cold Syrup }\end{array}$ & Throat/Cough Cold syrup & China \\
\hline 0032 & $1.61^{\mathrm{a}}$ & $<\mathrm{LOD}$ & 0.00014 & $<\mathrm{LOD}$ & $\begin{array}{l}\text { Chwan poi pei pa lo Natural } \\
\text { Herb Loquat Extract }\end{array}$ & Dietary/Herbal supplement & Hong Kong \\
\hline 0045 & 10.6 & 12.8 & 0.0009 & 0.0012 & Yin Chiao Herbal Extract & Dietary/Herbal supplement & China \\
\hline 0046 & 13.7 & 20.2 & 0.0012 & 0.0018 & Liuwei Dihuang Herbal extract & Dietary/Herbal supplement & China \\
\hline 0068 & 13.4 & $<$ LOD & 0.0012 & $<$ LOD & Leren Herbal Extract & Dietary/Herbal supplement & China \\
\hline 0069 & 6.5 & $<$ LOD & 0.00058 & $<$ LOD & Angelica Jujube Extract & Dietary/Herbal Supplement & China \\
\hline 0072 & 7.1 & $<\mathrm{LOD}$ & 0.00064 & $<\mathrm{LOD}$ & Unknown energy tonic & Dietary/Herbal supplement & China \\
\hline 0075 & 6.18 & $<$ LOD & 0.00055 & $<$ LOD & Yi Wang Jiang & Dietary/Herbal supplement & China \\
\hline 0080 & $4.87^{\mathrm{a}}$ & $<\mathrm{LOD}$ & 0.00044 & $<\mathrm{LOD}$ & $\begin{array}{l}\text { Fritillary and Loquat } \\
\text { Extract-Royal King Brand }\end{array}$ & Dietary/Herbal supplement & China \\
\hline 0081 & 10.7 & $<\mathrm{LOD}$ & 0.001 & $<\mathrm{LOD}$ & Shenji Royal Jelly in honey base & Dietary/Herbal supplement & China \\
\hline
\end{tabular}

The Panama 2006 DEG mass poisoning had products with percent DEG $v / v$ of $8.1 \%$ as a comparison value

${ }^{a}$ These results were initially below the LOD $(6.3 \mathrm{mcg} / \mathrm{ml})$ and therefore determined to be "detectable but not quantifiable". To provide a quantitative determination, the sample was reanalyzed using ten times the original volume and the correct initial concentration back-calculated

${ }^{\mathrm{b}}$ Converted mcg to gram and divided by density $(1.1 \mathrm{~g} / \mathrm{ml})$ to determine the $\mathrm{ml}$ of DEG and TEG. The value was then converted to percentage by multiplying by $100 \%$

LOD $=$ Level of Detection

1992) was more than 150 times higher than the highest daily dose estimated in our study $(0.09 \mathrm{mg} / \mathrm{kg})$.

The true minimum DEG dose associated with toxicity and lethality is unknown. However, DEG doses of 0.5$1.0 \mathrm{~g} / \mathrm{kg}$ in humans are associated with acute renal failure and even death. [15]. The highest estimated daily dose of DEG in this study was $0.09 \mathrm{mg} / \mathrm{kg}$ which is more than 5,000 times lower than the $0.5 \mathrm{~g} / \mathrm{kg}$ dose. Humans are thought to be more susceptible to the effects of DEG and acute oral lethal doses in rats are even higher (around $16 \mathrm{~g} / \mathrm{kg}$ ). [15].

A single study in humans reported that DEGcontaminated, polyethylene glycol (PEG) solution (used for whole-bowel irrigation) was given to patients without any reported acute health effects. These patients were given an average DEG dose of $11 \mathrm{mg}$ (range, 2-22 $\mathrm{mg}$ ) [16]. In our estimated dosing scenarios, the highest daily dose received would have been from sample $17(0.09 \mathrm{mg} / \mathrm{kg})$. Assuming a 70-kg weight, the overall estimated daily dose would have been $6.3 \mathrm{mg}$, which falls within the range mentioned previously without any adverse effects. To make this comparison, one has to assume that the PEG solution would have only been given once that day, which is reasonable based on the typical use of this product, so that the $11 \mathrm{mg}$ value represented a total daily ingested amount.

\section{Discussion}

If used as directed, the DEG in these products does not appear to pose an imminent health threat based on currently available data. It demonstrates that DEG values seen in the final product fall several orders of magnitude lower than what has been seen in past DEG mass poisonings. It also shows that estimated adult DEG doses from these products fall more than two orders of magnitude lower than levels associated with toxicity or lethality in the literature. However, the long-term risks of chronic exposures to these products are unknown. In addition, the possibility exists that people may ingest more than the recommended dosage or may ingest multiple products. Furthermore, certain subpopulations may be at greater risk for adverse effects from these products. Children were an intended recipient of at least five of the 15 DEG-positive products (specific mention was made on the labeling; see Table 2); children are likely to receive a higher dose per unit body weight than adults.

Topically applied agents with DEG are considerably less likely to cause harm because their transdermal absorption route is much less effective than the oral absorption route; however, the potential for toxicity may exist among those patients with burns or dermatologic conditions that disrupt the skin barrier. DEG absorption and toxicity has occurred 
Table 2 Dosing instructions as per package instructions for all products with detectable levels of DEG $(n=15)$

\begin{tabular}{|c|c|}
\hline $\begin{array}{l}\text { Sample } \\
\text { ID }\end{array}$ & Dosing instruction \\
\hline 003 & $\begin{array}{l}\text { Adults: } 2 \text { teaspoons }(1 \text { bottle }) \text { every } 4 \mathrm{~h} ;(1 \text { bottle }=10 \mathrm{ml}) \\
\text { Age } 6-12 \text { years old: } 1 / 2 \text { teaspoon }(1 / 2 \text { bottle }) \text { every } 4 \mathrm{~h} \text {; } \\
\quad(1 \text { bottle }=10 \mathrm{ml}) \\
\text { Children }<6 \text { years old: consult a doctor }\end{array}$ \\
\hline 016 & Over 2 years old: topical agent (few drops) \\
\hline 017 & $1-2$ bottles 3 times a day $(1$ bottle $=10 \mathrm{ml})$ \\
\hline 022 & $\begin{array}{l}1 \text { bottle } 2 \text { times a day }(1 \text { bottle }=10 \mathrm{ml}) \\
\text { Warning present that says "Keep away from children" }\end{array}$ \\
\hline 027 & Topical agent \\
\hline 029 & Over 12 years old: 1 bottle every $4 \mathrm{~h}(1$ bottle $=15 \mathrm{ml})$ \\
\hline 032 & $\begin{array}{l}\text { Adults: } 2 \text { teaspoons or } 10 \mathrm{ml} \text { every } 4 \mathrm{~h} \\
\text { Children: } 1 \text { teaspoon every } 4 \mathrm{~h}\end{array}$ \\
\hline 045 & 1 bottle 2 times a day $(1$ bottle $=10 \mathrm{ml})$ \\
\hline 046 & $\begin{array}{l}\text { Adults: } 10 \mathrm{ml} 2 \text { times a day } \\
\text { Children: "Decrease amount according to age" }\end{array}$ \\
\hline 068 & $10 \mathrm{ml} 2$ times a day \\
\hline 069 & $10 \mathrm{ml} 2$ times a day \\
\hline 072 & $\begin{array}{l}1-2 \text { bottles } 2 \text { times a day }(1 \text { bottle }=10 \mathrm{ml}) \text {; total } \\
\text { treatment }=30 \text { bottles }\end{array}$ \\
\hline 075 & Adults only: 1 bottle 2 times a day $(1$ bottle $=10 \mathrm{ml})$ \\
\hline 080 & $\begin{array}{l}\text { Adults and children: } 1 / 2-1 \text { teaspoon } 3-4 \text { times per day }(1 \\
\text { teaspoon }=12 \mathrm{~g})\end{array}$ \\
\hline 081 & $10 \mathrm{ml} 1$ time a day \\
\hline
\end{tabular}

among burn patients that received DEG-contaminated silver sulfadiazine burn cream [17].

Past medication-associated DEG mass poisonings have suggested that substitution of DEG for pharmaceutical grade glycerin, probably for financial gain, and failure to adhere to appropriate quality assurance procedures are the most likely reasons [2]. However, these events involved large amounts of DEG, not very small amounts as seen in this study. The exact origin of these trace amounts of DEG is unclear. The possibility of minor DEG contamination of raw ingredients during the raw ingredient and final product manufacturing process cannot be excluded. In these particular situations, DEG may simply be a minor impurity created during the manufacturing processes of chemicals used to formulate drugs and consumer products.

\section{Limitations}

A preferred method of estimating the potential toxicity risk from chemicals in humans is to compare known amounts of toxicants that have been absorbed into the body with established, validated values representing risk of minimal toxicity on a dose per kilogram basis. This estimation is often impossible, as is the case with DEG and TEG, due to
Table 3 Average estimated DEG dose for a $70 \mathrm{~kg}$ adult for samples with detectable DEG levels based on product dosing instructions $(n=15)$

\begin{tabular}{lll}
\hline Sample ID & $\begin{array}{l}\text { Estimated Single DEG } \\
\text { Dose in a 70 kg adult } \\
(\mathrm{mg} / \mathrm{kg})\end{array}$ & $\begin{array}{l}\text { Estimated Daily Maximum } \\
\text { DEG Dose in a 70 kg adult } \\
(\mathrm{mg} / \mathrm{kg})^{\mathrm{a}}\end{array}$ \\
\hline 0017 & 0.031 & 0.09 \\
0016 & $\mathrm{NA}$ & $\mathrm{NA}$ \\
0029 & 0.0033 & 0.02 \\
0046 & 0.002 & 0.004 \\
0068 & 0.002 & 0.004 \\
0081 & 0.0015 & 0.0015 \\
0045 & 0.0015 & 0.003 \\
0072 & 0.002 & 0.004 \\
0075 & 0.0009 & 0.002 \\
0069 & 0.0009 & 0.002 \\
0003 & 0.0008 & 0.005 \\
0080 & 0.0003 & 0.001 \\
0027 & $\mathrm{NA}$ & $\mathrm{NA}$ \\
0032 & 0.0002 & 0.001 \\
0022 & 0.0001 & 0.0002 \\
\hline
\end{tabular}

Limited historical data on median or average doses associated with toxicity or lethality from past medication-associated DEG mass poisonings are as follows: USA (1937), $1.0 \mathrm{ml} \mathrm{DEG} / \mathrm{kg}$ or approximately $1,118 \mathrm{mg} / \mathrm{kg}$ [11]; Argentina (1992), 14-174 mg DEG/kg [1, 12-14]; Haiti (1995), $1.34 \mathrm{ml} \mathrm{DEG/kg} \mathrm{or} \mathrm{approximately}$ $1,500 \mathrm{mg} / \mathrm{kg}$ [3].

$N A$ not applicable, topical agent

${ }^{\mathrm{a}} \mathrm{DEG}$ doses of $0.5-1.0 \mathrm{~g} / \mathrm{kg}$ have been associated with acute toxicity [16]

the paucity of information on minimum doses associated with toxicity and lethality in humans. Because the true minimum toxic and lethal doses for DEG in humans are unknown, comparisons are limited to data collected from past DEG poisonings. Toxic and lethal doses reported from past DEG mass poisonings have typically been calculated from postmortem testing [12-14], re-creation of hypothesized worst case-dosing scenarios [3], or the memory of survivors. Some of the toxic and lethal doses reported from these past mass poisonings were, at least in part, developed by incorporating information on the amount of DEG consumed over an extended period rather than from a single dose. These values were compared to individual, estimated single and daily dosing scenarios, which is not ideal. Therefore, reported toxicity levels may overestimate the minimum dose needed to cause acute or minimal toxicity. Exposure scenarios included in this study are hypothesized dosing situations based on manufacturer's instructions. These may not reflect exposures in real-life situations. This study only measured DEG and TEG concentrations in products collected from a single city in the USA, therefore our results may not reflect products from the entire USA. Furthermore, a large number of the 
samples in this study (20\%) could not be analyzed for technical reasons. Variability in how many individuals metabolize DEG may also play a role in toxicity that cannot be accounted for here.

It is important to note that many of the comparisons made in this study are comparing the estimated single or daily dose in this study to an estimated cumulative dose over a certain time period (not just one single or daily dose) from previous DEG mass poisonings, which is not ideal. For instance, in Haiti, the toxic dose was calculated by multiplying the DEG concentration in the bottle by how much liquid was missing from the bottle and dividing by the child's weight. However, in the absence of better human data on dose-response, using information from previous medication-associated DEG mass poisonings was among the best of remaining options.

\section{Conclusion}

DEG and TEG were found in several over-the-counter health products imported from Asian countries to the USA. DEG was detected at levels that were far below what has been reported in past, DEG mass poisonings. Estimated single and daily doses for adults were substantially below doses associated with toxicity in the limited literature on this topic. Health effects related to chronic exposure to DEG through these products is unknown. Ingredients besides those listed on a product's label may sometimes be found in unregulated products such as dietary supplements and consumers should be educated about these risks. Additional research focusing on why DEG is found in these products and on the minimum amount of DEG needed to result in toxicity is needed.

Disclaimer The findings and conclusions in this article are those of the authors and do not necessarily represent the views of the Centers for Disease Control and Prevention or the Agency for Toxic Substances and Disease Registry.

Use of trade names and commercial sources is for identification only and does not imply endorsement by the Centers for Disease Control and Prevention, or the U.S. Department of Health and Human Services.

\section{References}

1. Schep LJ, Slaughter RJ, Temple WA, Beasley DM (2009) Diethylene glycol poisoning. Clin Toxicol 47:525-535

2. Schier JG, Rubin CS, Miller D, Barr D, McGeehin MA (2009) Medication-associated diethylene glycol mass poisoning: a review and discussion on the origin of contamination. J Public Health Policy 30:127-143

3. O'Brien KL, Selanikio JD, Hecdivert C, Placide MF, Louis M, Barr $\mathrm{DB}$ et al (1998) Epidemic of pediatric deaths from acute renal failure caused by diethylene glycol poisoning. JAMA 279:1175-1180

4. Rentz ED, Lewis L, Mujica OJ, Barr DB, Schier JG, Weerasekera $\mathrm{G}$ et al (2008) Outbreak of acute renal failure in Panama in 2006: a case-control study. Bull World Health Organ 86:749-756

5. Bogdanich W, Hooker J (2007). From China to Panama, a trail of poisoned medicine. The New York Times. Available at: http:// www.nytimes.com/2007/05/06/world/06poison.html. Accessed 24 Sep 2009

6. Lin BL, Zhao ZX, Chong YT, Li JG, Zuo X, Tao Y et al (2008) Venous diethylene glycol poisoning in patients with preexisting severe liver disease in China. World J Gastroenterol 14:3236-3241

7. Bogdanich W (2007). Toxic Toothpaste made in China is found in US. The New York Times. Available at: http://www.nytimes.com/ 2007/06/02/us/02toothpaste.html. Accessed 24 Sep 2009

8. Vassiliadis J, Graudins A, Dowsett RP (1999) Triethylene glycol poisoning treated with intravenous ethanol infusion. J Toxicol Clin Toxicol 37:773-776

9. Ballantyne B, Snellings WM (2007) Triethylene glycol HO (CH2CH2O)3H. J Appl Toxicol 27:291-299

10. Borron SW, Baud FJ, Garnier R (1997) Intravenous 4methylpyrazole as an antidote for diethylene glycol and triethylene glycol poisoning: a case report. Vet Hum Toxicol 39:26-28

11. Calvery HO, Klumpp TG (1939) The toxicity for human beings of diethylene glycol with sulfanilamide. South Med J 32:1105-1109

12. Drut R, Quijano G, Jones MC, Scanferla P (1994) Hallazgos patologicos en la intoxicacion por dietilenglicol. Medicina (Buenos Aires) 54:1-5

13. Ferrari LA, Giannuzzi L (2005) Clinical parameters, postmortem analysis and estimation of lethal dose in victims of a massive intoxication with diethylene glycol. Forensic Sci Int 153:45-51

14. Schep LJ, Slaughter RJ (2005) Comments on diethylene glycol concentrations. Forensic Sci Int 155:233

15. Health Council of the Netherlands (2007). Diethylene glycol; healthbased recommended occupational exposure limit. Health Council of the Netherlands, The Hague (publication no. 2007/03OSH)

16. Woolf A, Pearson K (1995) Presence of diethylene glycol in commerical polyethylene glycol (PEG) solutions. J Toxicol Clin Toxicol 33:490

17. Cantarell MC, Fort J, Camps J, Sans M, Piera L (1987) Acute intoxication due to topical application of diethylene glycol. Ann Intern Med 106:478-479 